\title{
Role of low dose 256-slice CT perfusion imaging in predicting mediastinal lymph node metastasis of lung cancer
}

\author{
(iD) Li Yang \\ (iD) Lu Sun ${ }^{2}$ \\ (iD) Jian $\mathrm{Liu}^{3}$ \\ D Qiang Liu $^{4}$
}

1. Shandong University, Ji'nan, 250100 , China. 2. Cancer Research Center, Shandong Provincial Hospital, Jinan, 250021, China. 3. Department of Radiology, De Zhou, 253014, China. 4. Shandong Medical Imaging Research Institute, Shandong University, Ji'nan, 250021, China.

http://dx.doi.org/10.1590/1806-9282.65.6.761

\section{SUMMARY}

OBJECTIVE: CT perfusion (CTP) is an imaging technique that can be used to evaluate the changes in the microcirculation of tumor tissues. Our study aimed to investigate the role of CTP in predicting mediastinal lymph node metastasis.

METHODS: Clinical data of 58 patients who received surgical resection of lung cancer and lymph node dissection in our hospital from June 2012 to December 2014 were collected. Patients were divided into a positive lymph node metastasis group and a negative lymph node metastasis group. Parameters of CTP, including peak enhancement intensity (PEI), perfusion value (PV), as well as blood volume $(B V)$, were compared between the two groups. The receiver-operating characteristic $(R O C)$ curve was used to predict mediastinal lymph node metastasis.

RESULTS: The PV of the positive lymph node metastasis group was significantly higher than that of the negative group ( $p<0.001)$. The ROC curve analysis showed that PV can be used as an index to predict mediastinal lymph node metastasis of lung cancer. The sensitivity and specificity of a PV greater than $7.5 \mathrm{ml} \cdot \mathrm{min}^{-1} \cdot \mathrm{ml}^{-1}$ in predicting lymph node metastasis of lung cancer were $78.3 \%$ and 91.4 $\%$, respectively.

CONCLUSION: The PV of low dose CT perfusion can be used as an index for predicting mediastinal lymph node metastasis of lung cancer.

KEYWORDS: Lung Neoplasms. Perfusion Imaging. Tomography, X-Ray Computed. Lymph Nodes/pathology. Lymphatic Metastasis.

\section{INTRODUCTION}

Lung cancer is a malignant tumor that does not have very effective treatment strategies, and different types of lung cancers cause an unacceptably high mortality rate ${ }^{1}$. It has been reported that the deaths caused by lung cancer account for $25 \%$ of all cancer deaths ${ }^{1}$, and this proportion is expected to be further higher in the near future due to the increasing inci- dence of lung cancer caused by increasingly intensified environmental pollution as well as an increased number of smokers ${ }^{2-4}$. Previous studies indicated that various populations in poor health condition suffer from it ${ }^{5,6}$. A common type of metastasis of lung cancer, lymph node metastasis usually results in poor prognosis of patients with lung cancer ${ }^{7}$. It has 
been reported that about $20-40 \%$ of all cases of lung cancer will eventually progress to lymph node metastasis during the whole course of disease ${ }^{8}$. Up to now, surgical resection is still the primary treatment of lung cancer patients with lymph node metastasis. However, lymph node metastasis might be missed during surgical treatment, which in turn leads to shortened survival time and increased mortality rate 9. Therefore, it is of great clinical value to develop a method that can accurately predict lymph node metastasis of lung cancer.

Imaging techniques have been widely used in the diagnosis and prediction of various diseases, including lymph node metastases of different malignant tumors. It has been proved that the specificity of magnetic resonance imaging (MRI) in predicting lymph node metastases of rectal cancer can reach $95 \%$, which is much higher than that of triangulated category ${ }^{10}$. Neck ultrasound performed before surgery was also found to be able to provide reliable information on cervical lymph node metastasis of thyroid cancers, which can be used to guide surgical operations. As another clinically wide-applied imaging technique, CTR showed high accuracy in the early diagnosis of lung injury as well as lymph node metastases of malignant tumors. Therefore, it is reasonable to hypothesize that CTR can be used to predict lymph node metastases of lung cancer.

In this study, patients with different types of lung cancer were involved and divided into positive and negative lymph node metastasis groups based on the results of a pathological examination. The parameters of CTP were compared between those two groups, and the possibility of those parameters being applied in the prediction of lung cancer was discussed.

\section{METHODS}

\section{Objects}

Fifty-eight patients who received surgical resection of lung cancer and lymph node dissection in Shandong Provincial Hospital from June 2012 to December 2014 were collected. Inclusion criteria: a) Patients who had not received anti-tumor therapy before CTP examination; b) Patients who could hold their breath for a long time; c) Patients who did not have a history of allergy to iodinated contrast agents. Exclusion criteria: a) Patients with poor CTP images that could affect measurements; b) Patients whose diagnosis had not been confirmed by pathological examination. There were 38 males and 20 females, and the ages ranged from 35 to 85 years old with an average age of 66.7. Metastatic lymph nodes of lung cancer were found in 23 cases by pathological examination, and 35 cases showed no metastatic lymph nodes. No significant differences were found in basic information between the positive and negative lymph node metastasis groups (Table 1a). There were 28 cases of adenocarcinoma, 23 cases of squamous cell carcinoma, 2 cases of adenosquamous carcinoma and 5 cases of small cell lung cancer. Among the patients with metastatic lymph nodes, adenocarcinoma was found in 28 cases, squamous cell carcinoma in 11 cases, adenosquamous carcinoma in 1 case, and small cell lung cancer in 2 cases. All patients signed informed consent. The ethics committee of our hospital approved this study.

\section{CT scanning}

Preoperative CT examinations were performed using the Brilliance CT scanner (Philips, Netherlands). Patients fasted for 4 hours before being scanned, and their body weight was measured to determine the amount of contrast agent for injection. Patients were fixed in supine position and were asked to hold their breath. Then the area from the superior aperture of the thorax to the bottom of the lung was scanned to identify the lesion sites. Eight layers were selected along the maximum diameter

TABLE 1A. COMPARISON OF CLINICAL DATA BETWEEN POSITIVE AND NEGATIVE LYMPH NODE METASTASIS GROUPS

\begin{tabular}{l|l|l|l} 
Characteristics & \multicolumn{1}{c}{$\begin{array}{l}\text { Positive } \\
\text { lymph node } \\
\text { metastasis } \\
(\mathrm{n}=23)\end{array}$} & $\begin{array}{l}\text { Negative } \\
\text { lymph node } \\
\text { metastasis } \\
(\mathrm{n}=35)\end{array}$ & P-value \\
\hline Demographics & & \multicolumn{2}{l}{} \\
\hline Sex & 13 & 25 & 0.243 \\
\hline Male & 10 & 10 & \\
\hline Female & & 17 & 0.788 \\
\hline Age (years) & 12 & 18 & \\
\hline$\leq 65$ & 11 & & 0.006 \\
\hline$>65$ & & 25 & \\
\hline Tumor size & 8 & 10 & \\
\hline$\leq 5 \mathrm{~cm}$ & 15 & 12 & \\
\hline$>5 \mathrm{~cm}$ & & 4 & \\
\hline Pathological type & 16 & 12 & \\
\hline adenocarcinoma & 11 & & \\
\hline Squamous carcinoma & 3 & 12 & \\
\hline other & & & \\
\hline
\end{tabular}


of lesions for perfusion scanning. $50 \mathrm{ml}$ of nonionic contrast iohexol $(350 \mathrm{mgI} / \mathrm{ml})$ was injected through the median cubital vein at a speed of $4.0 \mathrm{ml} / \mathrm{s}$, and scanning was performed $5 \mathrm{~s}$ later with an interval of $5.8 \mathrm{~s}$. The total scanning time was $70 \mathrm{~s}$. Scanning parameters were slice thickness $5 \mathrm{~mm}$, tube voltage $120 \mathrm{kv}$, tube current $50 \mathrm{~mA}$, and matrix $512 * 512$. See Figure 1 for representative CT images.

\section{Image processing}

All images were processed using the Philips CT perfusion software. The region of interest (ROI) was selected on lesions and aorta or common carotid artery. Then PEI was calculated using the following formula: $\mathrm{PEI}=$ maximum enhancement intensity of the lesion-the CT value of scanning. PEI reflects the concentration of contrast agent in blood. PV was calculated using the following formula: $\mathrm{PV}=$ (the maximum initial slope of the time - density curve/PEI of the aorta at the same layer). PV represents the volume of blood perfusion in a unit time. BV represents the relative blood volume of the local area.

\section{Statistical analysis}

SPSS20.0 statistical software was used to analyze all the monitoring data. All data were expressed as mean \pm SD. Comparisons of perfusion parameters between two groups were performed using independent-samples t-test. A $\mathrm{P}<0.05$ was considered to be statistically significant. ROC curve analysis was performed to investigate the possibility of the application of CTR parameters in predicting metastatic lymph nodes.

\section{RESULTS}

Comparison of clinical data between the positive and negative lymph node metastasis groups

Fifty-eight patients who received surgical resection of lung cancer and lymph node dissection in our hospital from June 2012 to December 2014 were enrolled in this study. Patients included were 38 males and 20 females, and the ages ranged from 35 to 85 years with an average age of 66.7. Metastatic lymph

A
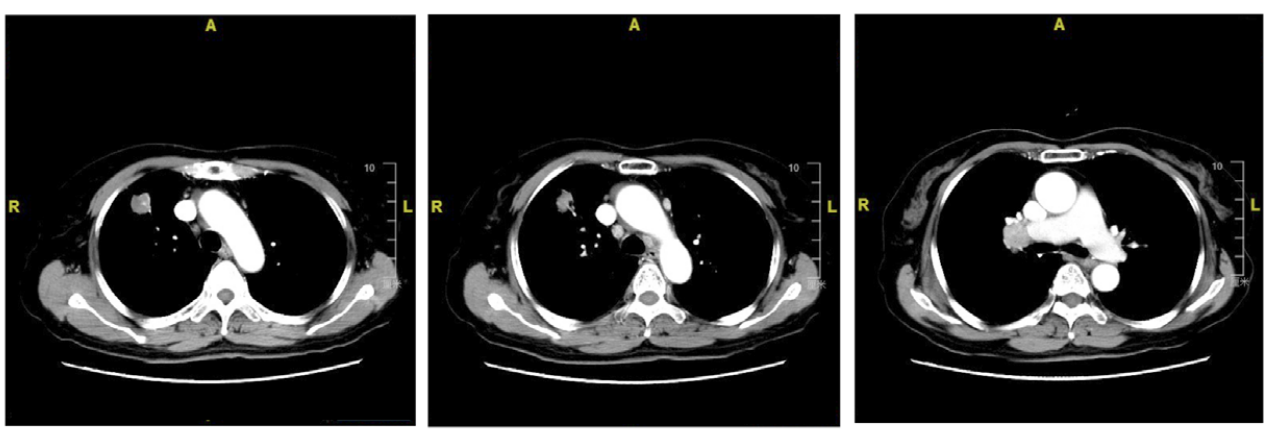

B
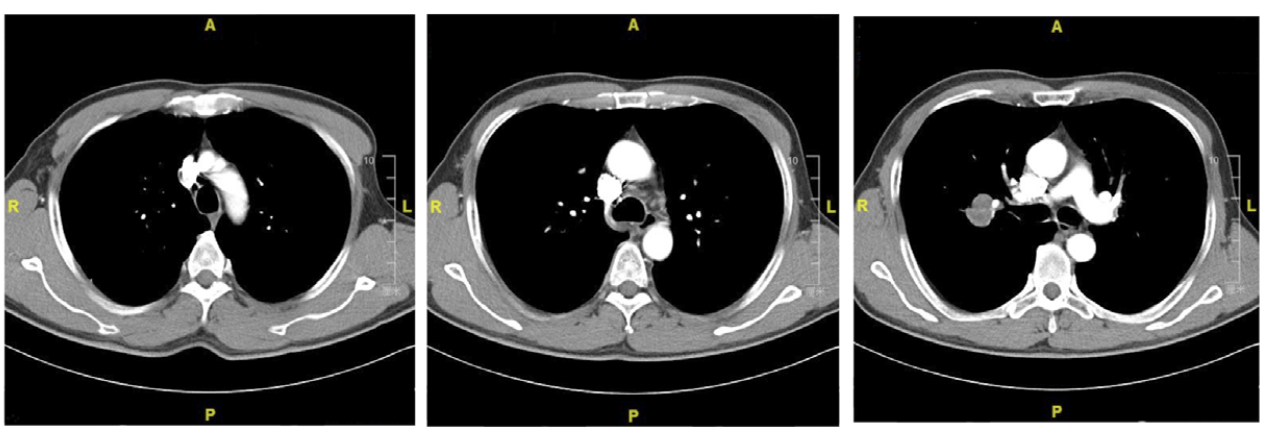

A Left: right upper lung cancer with the group 2 of mediastinal lymph node metastasis 1; Middle right upper group 2 lung cancer with mediastinal lymph node metastasis 2; Right: right upper lung group 10 cancer with lymph node metastasis.

B Left: Right upper lung cancer group 2 with no swelling of mediastinal lymph nodes; Middle right upper lung group 4 cancer with no swelling of mediastinal lymph nodes; Right: right upper lung group 7 cancer with no swelling of mediastinal lymph nodes. 
nodes of lung cancer were found in 23 cases by pathological examination, and 35 cases showed no metastatic lymph nodes. Statistical analysis showed that age and gender were not significantly correlated with the incidence of metastatic lymph nodes. However, the maximum diameter of the tumor in the positive lymph node metastasis group was significantly bigger than that in the negative lymph node metastasis negative group $(p=0.006)$. These data suggest that an increased tumor size can increase the risk of lymph node metastasis of lung cancer.

\section{Comparison of CTR parameters between the} positive and negative lymph node metastasis groups

As shown in Table $1 \mathrm{~b}$, the PV of the positive lymph node metastasis group was significantly higher than that of the negative group $(p<0.01)$. However, no significant differences in PEI and BV were found between the positive group and negative groups $(p>$ 0.05). These data suggest that PV, but not PEI and $\mathrm{BV}$, is closely correlated with the incidence of lymph node metastasis of lung cancer.

\section{Predictive ability of PV on lymph node metastasis}

The ROC curve analysis showed that the area under the ROC curve of PV in predicting lymph node metastasis was 0.921 (Figure 2), indicating that PV can be used to predict lymph node metastasis. The sensitivity and specificity of PV greater than $7.5 \mathrm{ml} \cdot \mathrm{min}^{-1} \cdot \mathrm{ml}^{-1}$ (as determined by Youden's index) in predicting lymph node metastasis of lung cancer were $78.3 \%$ and $91.4 \%$, respectively. These data suggest that PV can be used to accurately predict lymph node metastasis of lung cancer.

TABLE 1B. COMPARISON OF CTR PARAMETERS BETWEEN POSITIVE AND NEGATIVE LYMPH NODE METASTASIS GROUPS

\begin{tabular}{l|l|l|l|l} 
Parameter & $\begin{array}{l}\text { Positive } \\
\text { lymph node } \\
\text { metastasis } \\
(n=23)\end{array}$ & $\begin{array}{l}\text { Negative } \\
\text { lymph node } \\
\text { metastasis } \\
(n=35)\end{array}$ & t-value & $p$-value \\
& & & & \\
\hline PEI $(\mathrm{Hu})$ & $36.26 \pm 2.35$ & $33.11 \pm 1.41$ & 1.22 & 0.2267 \\
\hline $\mathrm{PV}\left(\mathrm{ml}^{-} \cdot \mathrm{min}^{-1} \cdot \mathrm{ml}^{-1}\right)$ & $10.35 \pm 0.82$ & $4.46 \pm 0.39$ & 7.20 & $<0.001$ \\
\hline $\mathrm{BV}\left(\mathrm{ml}^{-1} \cdot 100 \mathrm{~g}\right)$ & $5.13 \pm 0.50$ & $3.91 \pm 0.43$ & 1.83 & 0.0726 \\
\hline
\end{tabular}

FIGURE 2. ROC CURVE ANALYSIS TO INVESTIGATE THE PREDICTIVE ABILITY OF PV IN LYMPH NODE METASTASIS

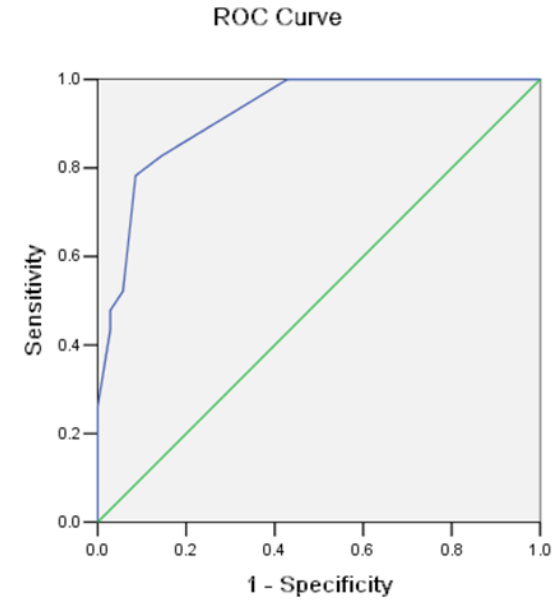

\section{DISCUSSION}

Lymph node status is closely correlated with the prognosis of patients with different types of cancers, including lung cancer. Therefore, the detection of lymph node status is the key to the diagnosis, treatment, and prognosis of cancer. It has been reported that the number of lymph nodes checked during a surgical operation can seriously affect the prognosis, and fewer lymph nodes examined can usually lead to shorter survival time. Various vulnerable groups have suffered from this. In addition, the ratio of the number of metastatic lymph nodes over the total number of lymph nodes is also a key factor that determined the prognosis of lung cancer patients. This conclusion is proved by another study that focused on colon cancer. In that study, Isik et al. reported that patients with stage III colon cancer usually have a ratio of the number of metastatic lymph nodes over the total number of lymph nodes higher than 0.25 , and this ratio was also proved to be able to accurately predict stage III colon cancer. Besides the value of metastatic lymph nodes in predicting the survival time of cancer patients, the number of metastatic lymph nodes also determines the recurrence of malignant tumors. Therefore, it is generally believed that the accurate diagnosis or prediction of metastatic lymph nodes is the key to the treatment of a considerable number of cancer patients.

A variety of methods have been developed to detect lymph node metastasis. Ferris et al. reported that the detection of expression levels of 3 related markers, including parathyroid hormone-related protein, pemphigus vulgaris antigen, and tumor-associated calcium signal transducer 1 , can be used to 
detect lymph node metastasis of neck and head cancer accurately, and the accuracy is higher than that of pathologic analysis and intraoperative pathology. The expression of some microRNAs is also closely related to the development of lymph node metastasis. Chen et al. reported that several microRNAs, such as miR-20a and miR-3147, were differentially expressed between early-stage cervical squamous cell carcinoma with and without lymph node metastasis. Therefore, those microRNAs can potentially be used as biomarkers of lymph node metastasis. Accurate imaging techniques such as MRI, CT, and ultrasound play pivotal roles in the diagnosis of various human diseases. Evans et al. reported that mean stiffness of shear wave ultrasound can serve as an independent predictor of lymph node metastasis in women with breast cancer, and the data obtained by this imaging technique can provide valuable information for the prediction of prognosis. In a study of lymph node metastasis of rectal cancer, diffusion-weighted magnetic resonance imaging was proved to be able to effectively predict lymph node metastasis and provide guidance for the selection of proper treatment strategy. Compared with other biomarkers such as the expression of microRNAs, which can be affected by environmental factors, CTP imaging provides a more reliable approach for the detection of lymph node metastasis.

CTP imaging is also a well-developed imaging technique that has been widely used in the diagnosis of various diseases. A 64-slice CT perfusion imaging was proved to be able to provide quantitative hemodynamic information in the diagnosis of mass-form- ing chronic pancreatitis and pancreatic adenocarcinoma. In the diagnosis of acute stroke, CTP imaging was also found to be able to provide valuable information on cerebral hemodynamics. In the studies of tumorigenesis, the quantitative and qualitative information of tumor angiogenesis obtained by CTP was used to predict the growth of cancer and guide the selection of oncologic therapies. In this study, a low dose 256-slice CT perfusion imaging system was used for the diagnosis of mediastinal lymph node metastasis of lung cancer. The current study found that the PV of CT perfusion, but not PEI or BV, was closely correlated with the incidence of lymph node metastasis of lung cancer. Moreover, based on the results of ROC curve analysis, PV was proved to be able to predict lymph node metastasis of lung cancer accurately. These data suggest that the PV of CT perfusion can potentially serve as a biomarker of the lymph node metastasis of lung cancer. In addition, consistent with previous studies, tumor size was also found to closely correlate with lymph node metastasis. Therefore, the size of the tumor should be considered in the diagnosis.

\section{CONCLUSION}

In conclusion, $\mathrm{PV}$ of $\mathrm{CT}$ perfusion was closely correlated with the incidence of lymph node metastasis of lung cancer, and PV was proved to be able to accurately predict lymph node metastasis. However, our study was limited by the small sample size and further studies with bigger sample size are needed to further confirm our conclusion.

\section{RESUMO}

OBJETIVOS: A perfusão por TC objetiva (CTP) é uma técnica de imagem que pode ser usada para avaliar as alterações na microcirculação de tecidos tumorais. Nosso estudo teve como objetivo investigar o papel da CTP na predição de metástases em linfonodos mediastinais.

MÉTODOS: Dados clínicos de 58 pacientes que receberam ressecção cirúrgica de câncer de pulmão e dissecção de linfonodos em nosso hospital de junho de 2012 a dezembro de 2014 foram coletados. Os pacientes foram divididos em grupo positivo para metástase linfonodal e grupo negativo para metástase linfonodal. Parâmetros de CTP incluindo pico de intensidade de realce (PEI) e valor de perfusão (PV), bem como volume de sangue (BV), foram comparados entre os dois grupos. A curva característica de operação do receptor (ROC) foi usada para predizer metástase linfonodal mediastinal.

RESULTADOS: PV do grupo de linfonodos metastáticos positivos foi significativamente maior do que o grupo negativo de linfonodos metastáticos $(p<0,001)$. A análise da curva ROC mostrou que a PV pode ser usada como um índice para predizer a metástase linfonodal mediastinal do câncer de pulmão. A sensibilidade e a especificidade da VP maior que $7,5 \mathrm{ml} \cdot \mathrm{min}^{-1} \cdot \mathrm{ml}^{-1}$ na predição de metástase linfonodal de câncer de pulmão foram de 78,3\% e 91,4\%, respectivamente.

CONCLUSÃo: A VP de perfusão por TC de baixa dose pode ser usada como um índice para a predição de metástase linfonodal mediastinal de câncer de pulmão.

PALAVRAS-CHAVE: Neoplasias pulmonares. Imagem de perfusão. Tomografia computadorizada por raios X. Linfonodos/patologia. Metástase linfática. 


\section{REFERENCES}

1. Siegel RL, Miller KD, Jemal A. Cancer statistics, 2016. CA Cancer J Clin. 2016;66(1):7-30.

2. Malvezzi M, Carioli G, Bertuccio P, Boffetta P, Levi F, La Vecchia C, et al. European cancer mortality predictions for the year 2017, with focus on lung cancer. Ann Oncol. 2017;28(5):1117-23.

3. Torre LA, Siegel RL, Jemal A. Lung cancer statistics. Adv Exp Med Biol. 2016;893:1-19.

4. Farley A, Aveyard P, Kerr A, Naidu B, Dowswell G. Surgical lung cancer patients' views about smoking and support to quit after diagnosis: a qualitative study. J Cancer Surviv. 2016;10(2):312-9.

5. Liang $Y$, Wang L. Alzheimer's disease is an important risk factor of fractures: a meta-analysis of cohort studies. Mol Neurobiol. 2017;54(5):32305.

6. Liang $Y$, Wang $L$, Yin $X$. The factor structure of the 12-item general health questionnaire (GHQ-12) in young Chinese civil servants. Health Qual Life Outcomes. 2016;14(1):136.
7. Guo D, Ni Y, LvX, Zhang Z, Ye P. Distribution and prognosis of mediastinal lymph node metastases of nonsmall cell lung cancer. J Cancer Res Ther. 2016;12(Suppl):120-5

8. Oyaizu T, Sagawa M, Sato M, Sakurada A, Matsumura Y, Ono S, et al. The pattern of mediastinal nodal involvement in lung cancer according to tumor-located lobe. Kyobu Geka. 1999;52(11):890-4.

9. Smeltzer MP, Faris N, Yu X, Ramirez RA, Ramirez LE, Wang CG, et al. Missed intrapulmonary lymph node metastasis and survival after resection of non-small cell lung cancer. Ann Thorac Surg. 2016;102(2):448-53.

10. Al-Sukhni E, Milot L, Fruitman M, Beyene J, Victor JC, Schmocker S, et al. Diagnostic accuracy of MRI for assessment of T category, lymph node metastases, and circumferential resection margin involvement in patients with rectal cancer: a systematic review and meta-analysis. Ann Surg Oncol. 2012;19(7):2212-23. 